\title{
WRF-simulated low-level jets over lowa: characterization and sensitivity studies
}

\author{
Jeanie A. Aird ${ }^{1}$, Rebecca J. Barthelmie ${ }^{1}$, Tristan J. Shepherd ${ }^{2}$, and Sara C. Pryor ${ }^{2}$ \\ ${ }^{1}$ Sibley School of Mechanical and Aerospace Engineering, Cornell University, Ithaca, New York, USA \\ ${ }^{2}$ Department of Earth and Atmospheric Sciences, Cornell University, Ithaca, New York, USA
}

Correspondence: Jeanie A. Aird (jaa377@ cornell.edu)

Received: 23 October 2020 - Discussion started: 14 November 2020

Revised: 27 May 2021 - Accepted: 24 June 2021 - Published: 28 July 2021

\begin{abstract}
Output from 6 months of high-resolution simulations with the Weather Research and Forecasting (WRF) model are analyzed to characterize local low-level jets (LLJs) over Iowa for winter and spring in the contemporary climate. Low-level jets affect rotor plane aerodynamic loading, turbine structural loading and turbine performance, and thus accurate characterization and identification are pertinent. Analyses using a detection algorithm wherein the wind speed above and below the jet maximum must be below $80 \%$ of the jet wind speed within a vertical window of approximately $20-530 \mathrm{~m}$ a.g.l. (above ground level) indicate the presence of an LLJ in at least one of the $147004 \mathrm{~km} \times 4 \mathrm{~km}$ grid cells over Iowa on $98 \%$ of nights. Nocturnal LLJs are most frequently associated with stable stratification and low turbulent kinetic energy (TKE) and hence are more frequent during the winter months. The spatiotemporal mean LLJ maximum (jet core) wind speed is $9.55 \mathrm{~m} \mathrm{~s}^{-1}$, and the mean height is $182 \mathrm{~m}$. Locations of high LLJ frequency and duration across the state are seasonally varying, with a mean duration of $3.5 \mathrm{~h}$. The highest frequency occurs in the topographically complex northwest of the state in winter and in the flatter northeast of the state in spring. Sensitivity of LLJ characteristics to the (i) LLJ definition and (ii) vertical resolution at which the WRF output is sampled is examined. LLJ definitions commonly used in the literature are considered in the first sensitivity analysis. These sensitivity analyses indicate that LLJ characteristics are highly variable with definition. Use of different definitions identifies both different frequencies of LLJs and different LLJ events. Further, when the model output is down-sampled to lower vertical resolution, the mean jet core wind speed height decreases, but spatial distributions of regions of high frequency and duration are conserved. Implementation of a polynomial interpolation to extrapolate down-sampled output to full-resolution results in reduced sensitivity of LLJ characteristics to down-sampling.
\end{abstract}

\section{Introduction}

The term low-level jet (LLJ) is applied to any lowertropospheric (approximately $2 \mathrm{~km}$ or below) maximum of horizontal winds that exhibits confined vertical extent (Markowski and Richardson, 2011). LLJs are observed episodically in most regions of the world (Rife et al., 2010; Krishnamurthy et al., 2015). LLJ formation mechanisms and manifestations span a range of scales from synoptic (i.e., mid-latitude cyclones) down to meso- (i.e., weather fronts) and microscales (i.e., topographic complexity and day-night surface heating) (Blackadar, 1957; Chen and Kpaeyeh, 1993; Lackmann, 2002; Jiang et al., 2007; Tay et al., 2020). Mechanisms commonly invoked to describe the forcing mechanisms include diurnal (day-night) variations in baroclinicity over sloping terrain (referred to as the Holton mechanism; Holton, 1967) and diurnal variations in boundary layer friction (referred to as the Blackadar mechanism; Blackadar, 1957). Both mechanisms invoke decoupling of the planetary boundary layer from the surface. In the case of the Blackadar mechanism, this decoupling is due to changes in turbulent mixing associated with day-night stability differences. These stability differences begin at sunset as the boundary layer rapidly stabilizes as the land surface cools, resulting in an inertial oscillation that is conducive to LLJ for- 


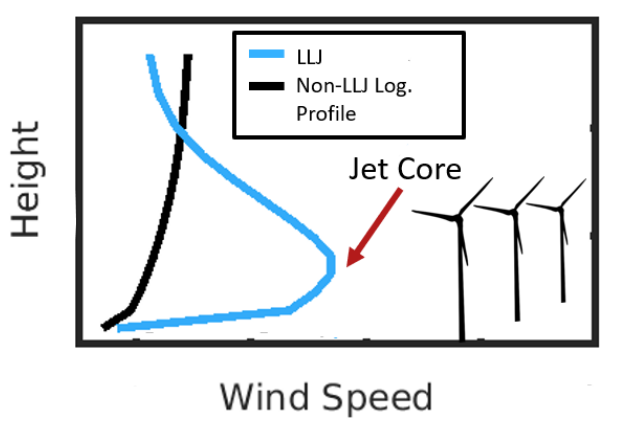

Figure 1. Illustrative graphic comparing a low-level jet (blue) wind speed profile and a standard logarithmic, non-LLJ wind speed profile. The wind speed maximum (jet core) in this depiction is at a height below a typical rotor plane, which would result in negative shear across the rotor plane.

mation. For the Holton mechanism, the decoupling can be attributed to pressure gradients arising from day-night heating of sloping terrain. Thus, both mechanisms result in a wind speed maximum and indicate that LLJs are most frequent under stable conditions and hence at nighttime (Holton, 1967) and in areas with topographic and/or land cover variability (Parish, 1982). LLJ characteristics, such as frequency, intensity and duration, also vary by seasonal and inter-annual timescales (Weaver et al., 2009; Liang et al., 2015).

In the continental US, the Southern Great Plains (SGP) LLJ is a persistent and prominent warm-season climate feature manifest at the synoptic scale; it extends over multiple degrees of longitude (i.e., having a width of hundreds of kilometers) and is coherent over many degrees of latitude (i.e., the jet is oriented along a south-north axis parallel to the Rocky Mountains) (Weaver and Nigam, 2008; Rife et al., 2010). This jet is centered at heights below $850 \mathrm{hPa}$ with a maximum (jet core; Fig. 1) most commonly observed between 300-625 m height (Rife et al., 2010) and is associated with moisture flux and summertime precipitation (Higgins et al., 1997; Berg et al., 2015). Wind profiler observations at $250 \mathrm{~m}$ intervals from $500 \mathrm{~m}$ a.g.l. (above ground level) to $19 \mathrm{~km}$ from a network of 31 stations across the Great Plains suggested that the mean LLJ height was approximately $1000 \mathrm{~m}$, and the mean duration was 2 to $4 \mathrm{~h}$ (Mitchell et al., 1995).

LLJs are observed across a range of spatial and temporal scales and in both onshore and coastal environments. Observational data derived using minisodars and wind profilers deployed at the ABLE facility in Kansas in the US Southern Great Plains indicated the presence of southerly (72\%) and northerly (28\%) LLJs, and the wind maxima typically occurred at 200-400 m a.g.l. The southerly LLJs exhibited higher mean duration $(\sim 6.7 \mathrm{~h}$ in the cold season and $6 \mathrm{~h}$ in the warm season) than northerly jets (Song et al., 2005). As depicted in Fig. 1, LLJs at, above and below these altitudes have the potential to impact the wind speed, turbulence and shear across typical wind turbine rotor planes, and analyses of both observational data and Weather Research and Forecasting (WRF) simulations indicate that LLJs frequently occur at heights that interact with the rotor plane (Gutierrez et al., 2014, 2017; Nunalee and Basu, 2014; Wagner et al., 2019; Aird et al., 2020).

Further, LLJs can increase wind farm performance through enhancing wake recovery (depending on atmospheric conditions and jet height) and may reduce wind turbine structural loading if the negative shear region of the jet interacts with the nacelle (Gadde and Stevens, 2021; Guttierez et al., 2017). If LLJ speed maxima occur at or near the rotor plane, enhancements in turbulence and shear have implications for aerodynamic blade loading and longevity (Kelley et al., 2005). As wind turbine heights, rotor diameters and capacities increase, it is likely that LLJs will interact more profoundly and frequently with the rotor plane, with increasing turbine dimensions resulting in more frequent interaction with the jet core (Barthelmie et al., 2020).

Despite the pertinence of LLJ characterization to wind resources and wind turbine operating conditions, a consistent and objective methodology for identifying and characterizing LLJ events is lacking. LLJ detection algorithms based on wind speed profiles employ

1. combined criteria based on both the absolute wind speed maximum and the difference in wind speed above and below the jet maxima (Bonner, 1968; Whiteman et al., 1997; Song et al., 2005);

2. a minimum absolute threshold for the difference in wind speeds above and below the profile maximum (Andreas et al., 2000; Banta et al., 2002);

3. a minimum threshold for wind speeds above and below the jet maxima defined as a percentage of the wind speed maximum;

4. a combination of (2) and (3), requiring both or one of the two thresholds to be met (Lampert et al., 2016; Baas et al., 2009).

Use of subjective and varying thresholds renders comparison of the frequency and/or intensity of LLJs across studies difficult. Adding to this ambiguity, some studies entirely lack a quantitative LLJ definition.

Variations in the resolution of observational data or model output used to identify LLJs also contribute to ambiguity, inconsistencies in characterization and/or a lack of generalizability (Kalverla et al., 2019; Whiteman et al., 1997; Bonner, 1968). For example, two analyses by Bonner (1968) and Whiteman et al. (1997) of LLJs in the same region used similar criteria but differed in that the second study added a fourth LLJ criterion based on enhanced vertical resolution of rawinsonde data (Bonner, 1968; Whiteman et al., 1997). This led to detection of LLJs with stronger wind speeds and lower wind maxima than were found in the initial study. Thus, due 
to frequent variation in LLJ definitions, it is pertinent to examine the types of LLJs (characteristics) that each definition extracts and the agreement between definitions. As LLJs occur due to atmospheric forcing on multiple scales (synoptic, meso, micro), it is possible that their wind speed profiles are a consequence of atmospheric conditions during the time of their generation, and jet profiles might be more likely to be extracted by certain definitions depending on atmospheric conditions or topography. A greater understanding of jets extracted through definitions used throughout the literature can thus reduce uncertainty in future studies and inform choice of definition.

Research presented herein uses output from a simulation conducted using the WRF model to characterize LLJ occurrence and characteristics. The specific WRF configuration (e.g., selection of the planetary boundary layer (PBL) scheme) and horizontal and vertical resolution have a clear impact on simulated flow within the atmospheric boundary layer. In general, despite these sensitivities, WRF has been demonstrated to exhibit skill in simulating LLJ events and the near-surface wind climate, although WRF has been shown to underestimate the magnitude of the LLJ maxima (Storm et al., 2008; Schepanski et al., 2015; Vanderwende et al., 2015; Squitieri and Gallus, 2016; Smith et al., 2018; Gevorgyan, 2018; Pryor et al., 2020a). Here, we do not further explore these dependencies but rather analyze WRF output to (i) develop a seasonal LLJ analysis for a warm and a cool season in the contemporary climate over a region within the US with high wind turbine densities and topographic variability, (ii) quantify the dependence of the LLJ characteristics (frequency, intensity, duration) and rotor plane conditions to the precise criteria used to identify LLJs, and (iii) investigate the impact of vertical resolution on LLJ characteristics using full-resolution and down-sampled WRF output.

\section{Methodology}

\subsection{WRF simulations}

The Weather Research and Forecasting Model (WRF) is a mesoscale numerical weather prediction model that is widely used in wind energy assessment and forecasting applications, such as predicting the impact of climate change on wind power generation and creating wind energy production estimates offshore and onshore (Pryor et al., 2020b; Salvação and Soares, 2018; Prósper et al., 2019). A highresolution WRF (v3.8.1) simulation is conducted using a nested domain where the outer domain (D01) spans $150 \times$ $150,12 \mathrm{~km} \times 12 \mathrm{~km}$ grid cells and encompasses much of the US Midwest, while the inner domain (D02), centered over Iowa, comprises $246 \times 204,4 \mathrm{~km} \times 4 \mathrm{~km}$ grid cells (Pryor et al., 2020c) (Fig. 2). This horizontal resolution has been found to be most optimal when simulating nocturnal LLJs when compared to higher (and lower) resolutions (Smith et al., 2018). A time step of $72 \mathrm{~s}$ is used for D01, while the time step in D02 is $24 \mathrm{~s}$. A total of 57 vertical sigma layers are employed and there are 25 levels below approximately $530 \mathrm{~m}$ a.g.l. Below $250 \mathrm{~m}$ a.g.l., the vertical spacing is approximately $15 \mathrm{~m}$. Analyses presented here use model output sampled once hourly (at the top of the hour) for December 2007 to May 2008 and thus consider over 4300 profiles for each grid cell within a sub-domain (D03) comprising $147 \times 100$ grid cells that encompasses the state of Iowa (Fig. 2). Iowa is selected as the focus for this work due to the high density of wind turbines (over $11 \mathrm{GW}$ of installed capacity) (American Clean Power, 2020) and observational research that has indicated a high frequency of extreme positive wind shear, which may be associated with LLJs (Walton et al., 2014). Key physics settings in the simulation presented here parallel those used in a similar study of the Orinoco LLJ over South America (Jiménez-Sanchéz et al., 2019); i.e., the Mellor-Yamada-Nakanishi-Niino (MYNN) 2.5 (Nakanishi and Niino, 2006) PBL scheme is used, along with the MM5 surface layer scheme (Beljaars, 1995) and the Noah land surface model (Tewari et al., 2004). The MYNN scheme is selected as it has been validated previously for WRF simulations in the Great Plains and shown to adequately model the PBL height when compared to observations (Zhang et al., 2020). Further, studies of LLJs in the Great Plains indicate that nocturnal LLJ characteristics may be less sensitive to the scheme employed than vertical resolution; the MYNN scheme has been shown to have minimal mean absolute error when simulating key jet core conditions, particularly with fine vertical grid spacing and a high model top pressure level such as that utilized in this simulation $(50 \mathrm{hPa})$ (Smith et al., 2018; Jahn and Gallus, 2018). Note that in all analyses presented herein, only wind speeds within the lowest $530 \mathrm{~m}$ of the atmosphere are considered. This implicitly limits the detection of LLJs to levels below that height.

\subsection{Seasonal analysis: LLJ identification and meteorological conditions}

The seasonal analysis of LLJ characteristics over Iowa is developed using a detection algorithm that employs a variable criterion of $20 \%$, applied to WRF output for all grid cells. This detection algorithm means that an LLJ is identified as present in a given profile if the wind speeds above and below the wind speed maximum have magnitudes that are at least $20 \%$ below the maximum (jet core) wind speed. Thus, the threshold varies based on the maximum value in each wind speed profile. Cumulative density functions of atmospheric parameters conditionally sampled based on the presence or absence of an LLJ are used to describe the conditions associated with LLJs. Parameters are considered in the vertical length of 50 to $150 \mathrm{~m}$ a.g.l., representing the rotor span of a typical wind turbine (not modeled here) with a rotor radius of $50 \mathrm{~m}$ and hub height of $100 \mathrm{~m}$. 


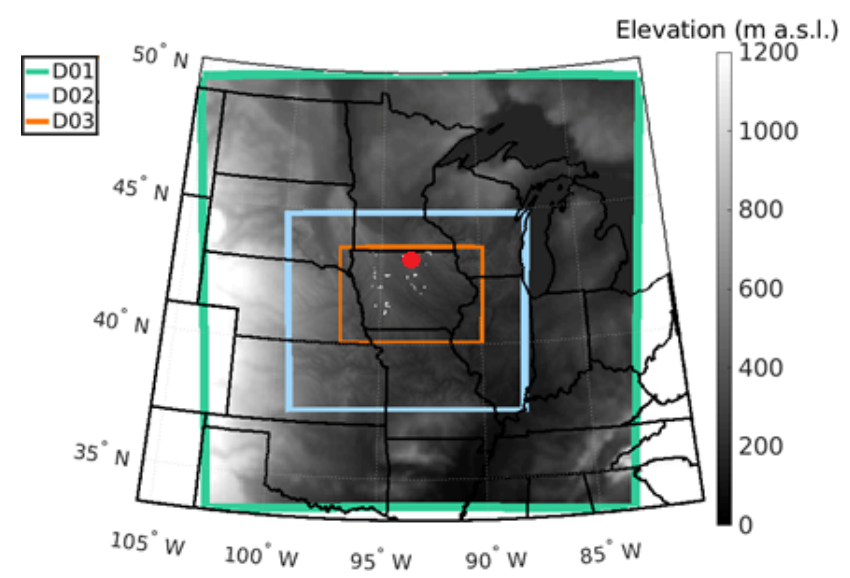

Figure 2. Terrain elevation and domains used in the WRF simulation (D01, D02) and the region from which wind profiles are analyzed (D03). White markers indicate wind turbine locations in 2014 (Hoen et al., 2021). The red marker indicates the approximate location of the grid cell with the highest LLJ frequency that is examined in Sect. 3.2.

The parameters considered are (a) mean turbulent kinetic energy (TKE) across the rotor plane derived by the PBL scheme, (b) wind speed at a nominal hub height of $100 \mathrm{~m}$ a.g.l., (c) the median Richardson number across the nominal rotor plane $\left(R i_{\text {Rotor }}\right)$ specified as 50 $150 \mathrm{~m}$ a.g.l. (Eq. 1 ) and (d) mean shear $(\alpha)$ across the nominal rotor plane (Eq. 2).

$$
\begin{aligned}
& R i_{\text {Rotor }}=\frac{2\left(Z_{2}-Z_{1}\right) g}{\theta_{Z_{2}}+\theta_{Z_{1}}}\left[\frac{\theta_{Z_{2}}-\theta_{Z_{1}}}{\left(u_{Z_{2}}-u_{Z_{1}}\right)^{2}+\left(v_{Z_{2}}-v_{Z_{1}}\right)^{2}}\right] \\
& \alpha=\left(\frac{U_{Z_{2}}-U_{Z_{1}}}{Z_{2}-Z_{1}}\right),
\end{aligned}
$$

where $U, u, v$ and $\theta$ represent wind speed $U$, wind speed components $u$ and $v$, and virtual potential temperature, respectively, at height $Z$ a.g.l. $R i_{\text {Rotor }} \sim 0$ is indicative of nearneutral stability, $R i_{\text {Rotor }}>0.25$ indicates stable conditions, and $R i_{\text {Rotor }}<0$ indicates unstable conditions (Grachev et al., 2013).

The $R i_{\text {Rotor }}$ is similar to the bulk Richardson number (Stull, 1988) but describes the dynamical stability across the wind turbine rotor (Nunalee and Basu, 2014). $R i_{\text {Rotor }}$ and wind shear are calculated across each sigma layer in the nominal wind turbine rotor plane (six sigma layers fall approximately within this range). Thus, positive and negative shear due to LLJs are described at multiple heights within the rotor plane. TKE is also calculated at each of the six heights within the rotor plane. Mean TKE and shear and median $R i_{\text {Rotor }}$ are then calculated from these points to approximate the central tendencies of rotor plane characteristics during non-LLJ and LLJ events. All variables except $R i_{\text {Rotor }}$ are computed using output sampled at an hourly time step, while $R i_{\text {Rotor }}$ is computed using variables output at $3 \mathrm{~h}$ intervals.
Probability distributions for LLJ characteristics, including duration and the jet core height, are also examined. If an LLJ occurs in a grid cell, the cell is flagged for each hour of occurrence. To calculate duration, these flags are counted for each consecutive LLJ occurrence, representing the length of time in which output from a given grid cell indicates the presence of an LLJ.

\subsection{Sensitivity analyses}

Following development of the seasonal analysis, two sensitivity analyses are performed (Table 1). The first sensitivity analysis (A) examines the impact of different detection algorithms on the resulting LLJ analysis. LLJs are detected and characterized using both (i) fixed criteria, i.e., a difference in wind speed above and below the wind speed maximum quantified in absolute terms (Andreas et al., 2000; Banta et al., 2002), and (ii) variable criteria, i.e., a difference in wind speeds above and below the wind speed maximum expressed as a percentage of the wind speed maximum. Often, these two types of criteria are used in conjunction, requiring a fixed or variable threshold or a fixed and variable threshold to be met (Baas et al., 2009; Lampert et al., 2016). This study examines both definitions separately to define the LLJs extracted under both types of thresholds. The criteria are grouped into five classes based on strictness and usage in the literature, from the least strict $\left(1 \mathrm{~m} \mathrm{~s}^{-1}\right.$ fixed, $10 \%$ variable) to the strictest $\left(5 \mathrm{~m} \mathrm{~s}^{-1}\right.$ fixed, $50 \%$ variable) (Table 2). Threshold strictness increases across groups in increments of $1 \mathrm{~m} \mathrm{~s}^{-1}$ for fixed and $10 \%$ for variable. Criteria group 2 features definitions most commonly used in tandem or uniquely in previous LLJ studies ( $2 \mathrm{~m} \mathrm{~s}^{-1}$ fixed, $20 \%$ variable).

Sensitivity to the LLJ definition employed is first demonstrated irrespective of domain-wide variations in topography using the WRF grid cell with the highest LLJ frequency according to the seasonal study developed initially $\left(43.7467^{\circ} \mathrm{N}, 92.2784^{\circ} \mathrm{W}\right)$. Results are presented in terms of the mean LLJ profiles and the marginal probability of LLJs produced by each criterion. From this, a relative frequency of disagreement is calculated between the two LLJ definitions in each criteria group, indicating how often definitions (for each level of strictness) identify different LLJ events (i.e., how frequently variable criteria identify LLJs when fixed criteria do not and the converse).

After the initial sensitivity is demonstrated, distributions of LLJ magnitude, duration and jet core height are compared across the entire domain for each LLJ detection algorithm. The domain-wide temporal LLJ frequency is compared for thresholds in criteria group $2\left(2 \mathrm{~m} \mathrm{~s}^{-1}\right.$ fixed, $20 \%$ variable) to examine definition sensitivity across varying terrain for each criteria type.

Sensitivity analysis B is conducted to examine whether and by how much LLJ characteristics change with the vertical resolution at which the WRF output is sampled. Wind speed output is down-sampled to a half and a quarter of 
Table 1. Summary of the LLJ sensitivity studies A and B.

\begin{tabular}{llll}
\hline $\begin{array}{l}\text { Sensitivity } \\
\text { study }\end{array}$ & Outline and purpose & $\begin{array}{l}\text { LLJ identification } \\
\text { criteria }\end{array}$ & $\begin{array}{l}\text { Output vertical } \\
\text { sampling }\end{array}$ \\
\hline A & $\begin{array}{l}\text { Impact of different detection } \\
\text { algorithms }\end{array}$ & $\begin{array}{l}\text { Five variable and five fixed } \\
\text { thresholds (Table 2) }\end{array}$ & Full resolution \\
\hline B & Vertical resolution of wind speed & $\begin{array}{l}20 \% \text { Reduction in wind } \\
\text { speed above and below } \\
\text { output down-sampled }\end{array}$ & $\begin{array}{l}\text { Full, half down- } \\
\text { sample, quarter down- } \\
\text { sample }\end{array}$ \\
\hline
\end{tabular}

Table 2. Criteria groups for sensitivity study A and LLJ extraction algorithm thresholds.

\begin{tabular}{lrrrrr}
\hline Criteria group & 1 & 2 & 3 & 4 & 5 \\
\hline Fixed criterion threshold $\left(\mathrm{m} \mathrm{s}^{-1}\right)$ & 1 & 2 & 3 & 4 & 5 \\
Variable criterion threshold (percent of maximum LLJ wind speed) & 10 & 20 & 30 & 40 & 50 \\
\hline
\end{tabular}

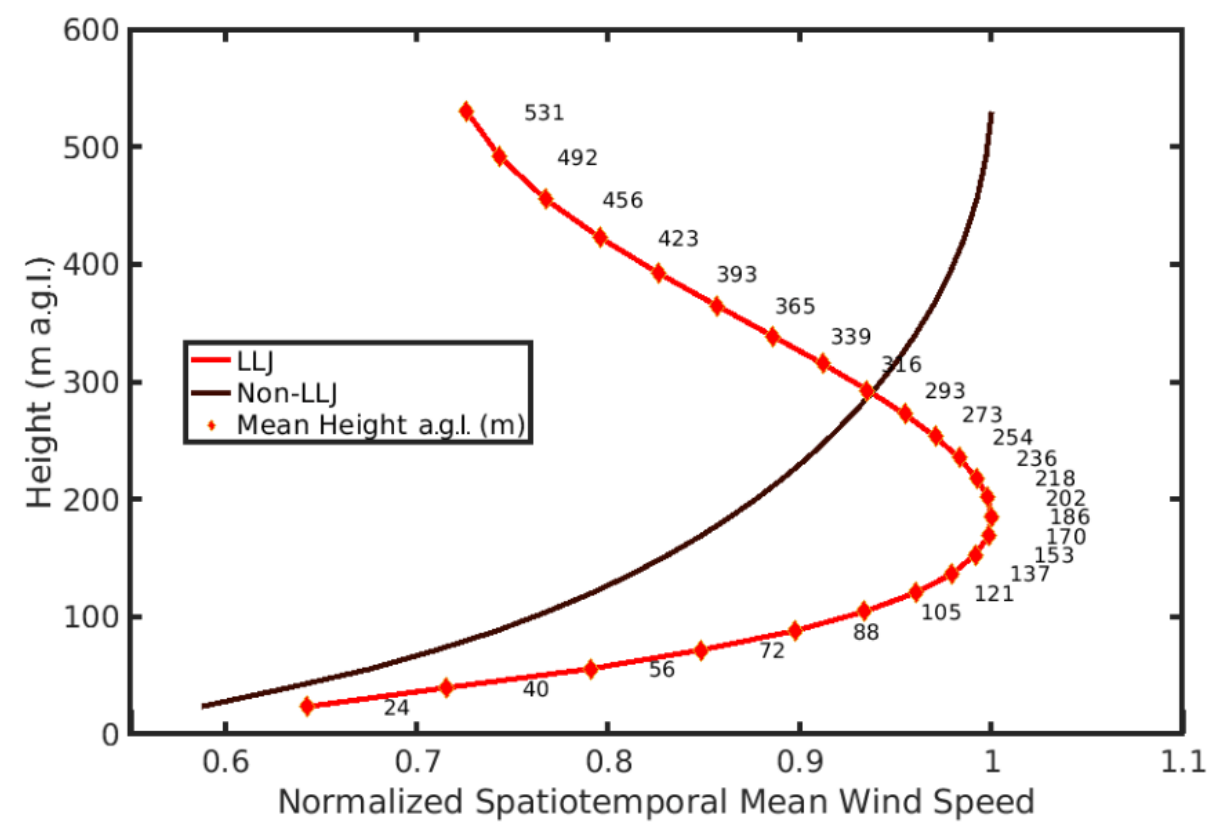

Figure 3. Mean wind speed profiles during all hours identified as exhibiting LLJs and those without (non-LLJ). These profiles are computed from all hourly profiles (in the entire time domain from December 2007 to May 2008) from all grid cells, and each profile is normalized by the maximum wind speed after compositing. The LLJ detection algorithm uses a variable threshold of $20 \%$. Both mean wind speed profiles are plotted against the temporally and spatially averaged mean height of each vertical level.

the simulation resolution to investigate effects of wind speed profile data resolution when all other factors are unchanged. Results of this analysis are presented in terms of the spatiotemporal mean LLJ wind speed profiles, magnitude of the LLJs, duration, fraction of LLJs that impinge upon the rotor plane (defined as heights from 50-150 m a.g.l.), and the spatial patterns of LLJ frequency and duration.

\section{Results}

\subsection{LLJ characterization using a variable threshold of $20 \%$}

A clear jet core is evident when comparing spatiotemporal mean LLJ and non-LLJ profiles normalized by each profile's respective wind speed maximum (Fig. 3). The spatiotemporal mean LLJ core wind speed computed using wind speed values across each vertical layer for all hours from all grid cells is approximately $9.55 \mathrm{~m} \mathrm{~s}^{-1}$ and is centered at about 

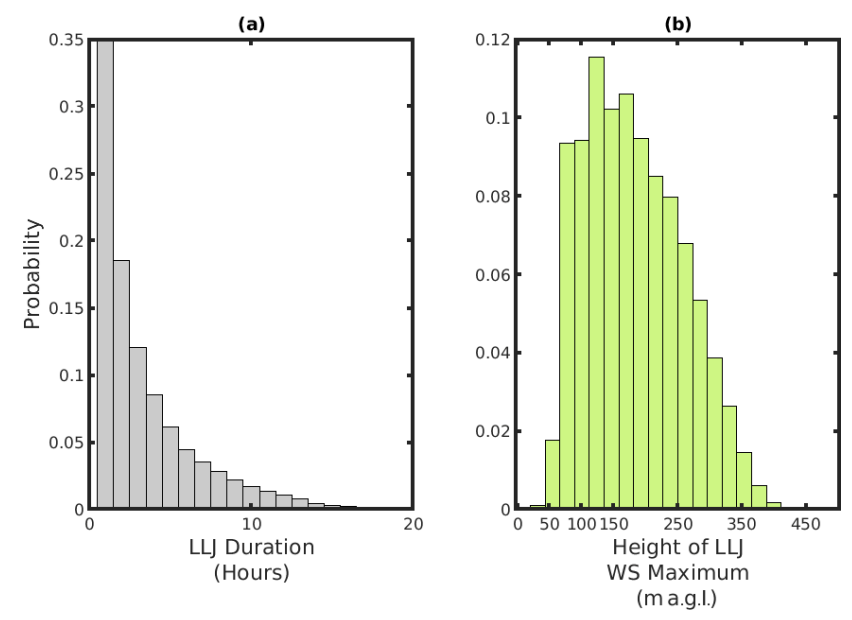

Figure 4. Probability distributions from a domain-wide sample of all hourly realizations of vertical LLJ wind speed (WS) profiles for (a) LLJ duration and (b) height of the jet core. Note that LLJs with durations of over $20 \mathrm{~h}$ were identified, but the distribution is truncated at $20 \mathrm{~h}$ for legibility.

183 ma.g.l. Approximately $96 \%$ of LLJs exhibit jet core wind speeds of $3-25 \mathrm{~m} \mathrm{~s}^{-1}$ and are thus likely to be associated with normal wind turbine operation. Over the analysis period of 6 months there is evidence of an LLJ in one or more grid cells on nearly $98 \%$ of nights (between 18:0006:00 LT - local time), and nearly $65 \%$ of LLJs occur at night. Daytime LLJs are more frequent in the winter months (December-February). Approximately $40 \%$ of winter LLJs occur during daytime hours as compared to $30 \%$ during spring (March-May).

A total of $30 \%$ of LLJs are evident only in individual hours, but $4 \%$ have a duration of $>10 \mathrm{~h}$ (Fig. 4a). The modal value of LLJ height in the vertical window considered is between 100-150 ma.g.l. (the upper extent of the nominal rotor plane), and approximately $39 \%$ of LLJs have a wind speed maximum within the nominal rotor plane of $50-150 \mathrm{~m}$ (Fig. 4b).

Consistent with expectations, LLJs are more prevalent during stable conditions as indicated by cumulative density functions of $R i_{\text {Rotor }}$, conditionally sampled by the presence or absence of an LLJ (Fig. 5a). Approximately $15 \%$ of LLJs occur during hours when $R i_{\text {Rotor }}<0.25$, but the spatiotemporal median $R i_{\text {Rotor }}$ is 0.87 when the detection algorithm indicates the presence of an LLJ. Conversely, $60 \%$ of non-LLJ profiles occur with $R i_{\text {Rotor }}<0.25$, and the median non-LLJ $R i_{\text {Rotor }}$ is 0.15 . Also consistent with a priori expectations, LLJ events are associated with substantially lower TKE within the rotor plane. The median TKE within the rotor plane when LLJs are identified is $0.056 \mathrm{~m}^{2} \mathrm{~s}^{2}$, while the non-LLJ median rotor plane TKE is $0.37 \mathrm{~m}^{2} \mathrm{~s}^{2}$ (Fig. 5b). Almost two-thirds (61\%) of LLJs exhibit wind speed maxima above the rotor plane. Thus, a greater diversity (i.e., wider distribution) of wind shear conditions occur
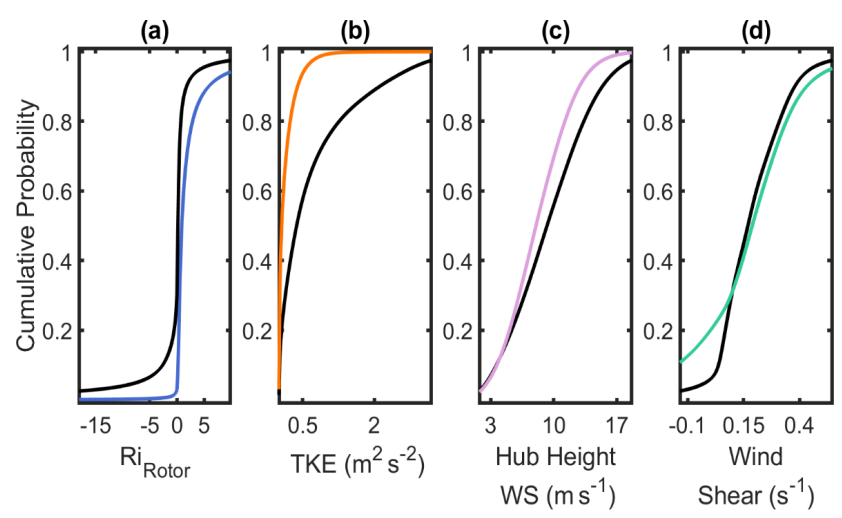

Figure 5. Domain-wide spatiotemporal cumulative density functions for conditions during hours with LLJ (colored) and without (non-LLJ) (black). Quantities (shear, TKE and $R i_{\text {Rotor }}$ ) are calculated at each of the six vertical layers within the nominal rotor plane (50 to $150 \mathrm{ma.g.1}$.), then averaged to obtain central tendencies (mean, median): (a) median $R i_{\text {Rotor }}$, (b) mean TKE across the rotor plane, (c) hub height wind speed (wind speed at $100 \mathrm{~m}$ a.g.l.), (d) mean wind shear across the nominal rotor plane. For enhanced visibility, each subfigure is cropped at the 2.5 th and 97.5 th percentile values of non-LLJ parameters.

during LLJs (Fig. 5d), and there is evidence that very-nearsurface (i.e., low-altitude) LLJs can induce negative shear across the nominal rotor plane (Gutierrez et al., 2017). Wind speeds at the nominal hub height of $100 \mathrm{~m}$ a.g.l. are higher on average during non-LLJ conditions (Fig. $5 \mathrm{c}$ ), with a median of $9.24 \mathrm{~m} \mathrm{~s}^{-1}$ when compared to the LLJ median of $8.02 \mathrm{~m} \mathrm{~s}^{-1}$. This is likely due to a complex combination of the following factors: (a) the LLJ selection criteria are more readily met at lower wind speeds (Sect. 3.2); (b) microscale to mesoscale features (i.e., locally forced LLJs) are less readily established under conditions with strong synoptic forcing that generates high geostrophic wind speeds (Mortarini et al., 2018); and (c) depending on the precise height under consideration and the depth of the boundary layer, stable stratification may result in decreased vertical exchange of momentum (Barthelmie et al., 2013).

The mean duration and frequency of LLJs exhibit a clear dependence on geographical location and season (Fig. 6). On average, LLJs last slightly longer and occur more frequently in the winter months. The mean duration averaged over space and time is $3.6 \mathrm{~h}$ in winter and $3.4 \mathrm{~h}$ in spring. In spring, the northeast of Iowa experiences the highest frequency of LLJs, with the detection algorithm using a $20 \%$ variable threshold detecting LLJs on up to $20 \%$ of hours. The mean LLJ duration in this season and region of Iowa approaches $4.5 \mathrm{~h}$. Conversely, the western part of the state is characterized by higher terrain elevation and larger terrain variability and exhibits a wintertime maximum of both LLJ duration and frequency (27\% of hours) (Fig. 6) consistent with formation of LLJs resulting from drainage-flow-induced gravity waves (Prabha et al., 2011; Udina et al., 2012). 

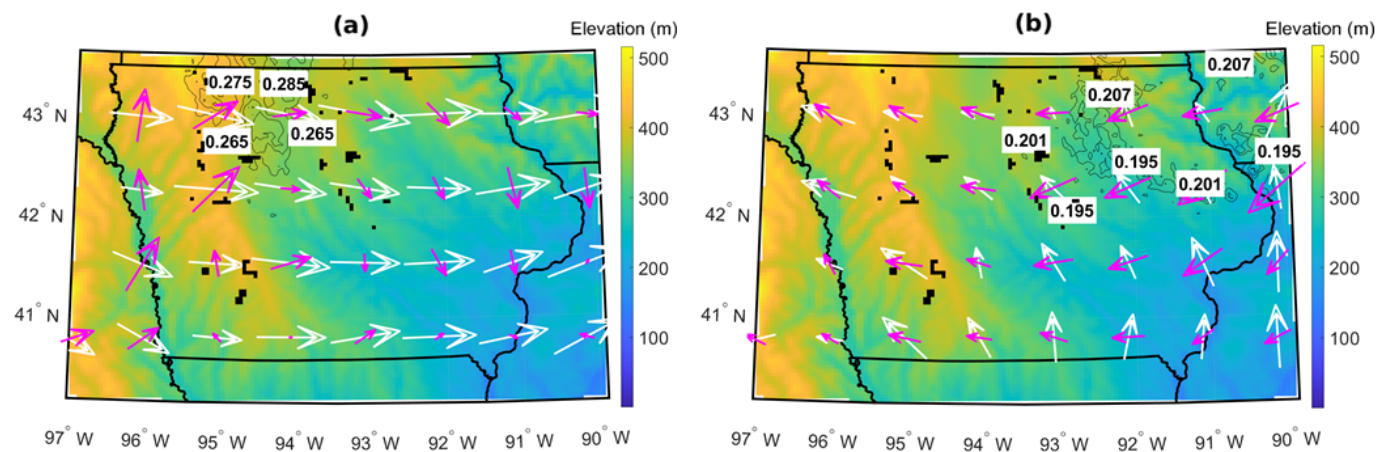

(c)
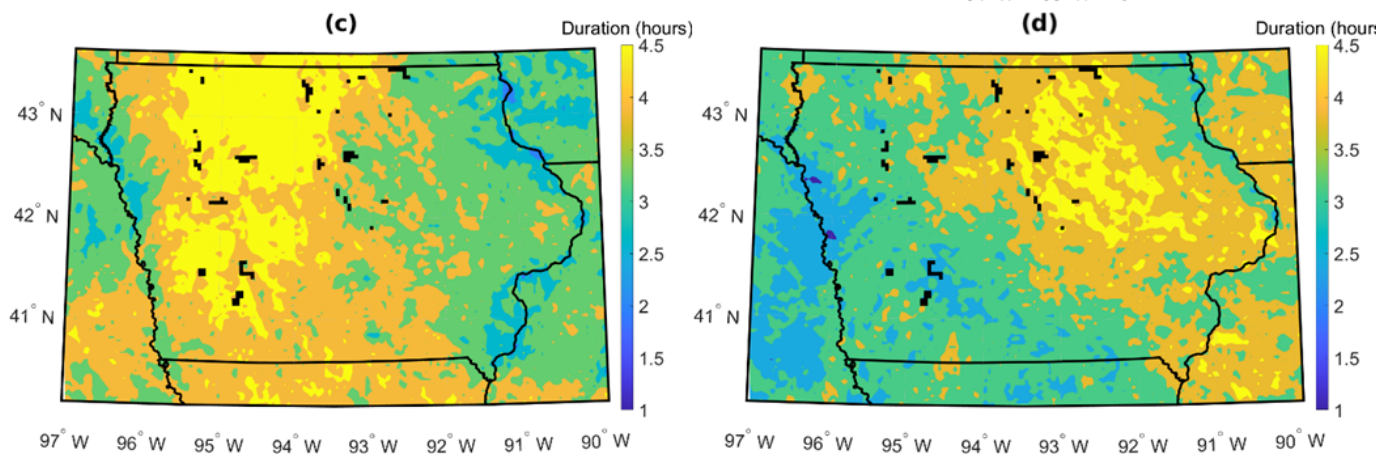

Figure 6. (a) December-February. Regional elevation (m) with contours of regions of highest $10 \%$ of LLJ frequency (>0.26). Average LLJ (pink) and non-LLJ (white) wind vectors at nominal turbine hub height of $100 \mathrm{~m}$. (b) March-May. Regional elevation (m) with contours (black; contour values given in white markers) of regions of highest $10 \%$ of LLJ frequency ( $>0.19)$. Average LLJ and non-LLJ wind vectors at nominal turbine hub height of $100 \mathrm{~m}$. (c) December-February. Regional mean LLJ duration. (d) March-May. Regional mean LLJ duration. Black markers indicate wind turbine locations.

Mean wind vectors at a nominal wind turbine hub height of $\sim 100 \mathrm{~m}$ a.g.l. under LLJ and non-LLJ conditions suggest marked differences in both the mean wind direction in winter and spring and the mean wind directions (averaged in polar space) associated with LLJ and non-LLJ conditions (Fig. 6a and b). The mean winter flow direction for both LLJs and non-LLJs exhibits a westerly component for all grid cells considered, while easterly flow components are more common during the spring months. Rotor plane wind directions during LLJ events exhibit more spatial variability than during non-LLJ events. Springtime LLJs exhibit less spatial variability in wind direction than winter LLJs, coinciding with the increased frequency of winter LLJs compared to spring LLJs. Springtime LLJs are most frequently associated with northeasterly flow over the northeast of the state, while winter LLJs are most frequently associated with southwesterly flow in the northwest of the state. Analyses of the seasonality and spatial variability in mean LLJ wind directions indicate that, during winter over the western portion of the state, LLJs are predominantly associated with southerly wind directions, while over eastern Iowa the LLJs are associated with more northerly flow (Fig. 6a). Conversely, springtime LLJs over almost all of the state are dominated by easterly wind directions and are generally of substantially shorter duration over the western half of Iowa (Fig. 6).
This variation in LLJ intensity and duration by season and location may reflect differences in LLJ genesis mechanisms. The western portion of Iowa exhibits substantially more complex terrain and thus may be subject to stronger thermal (radiative) and dynamic forcing at the meso- and microscales. Consequently, this region may be subject to density-driven slope and valley winds that may induce LLJs via the Holton mechanism, particularly during winter (Holton, 1967). The increase in LLJ frequency in the northeast during the spring is also associated with an increase in LLJ speed when compared to LLJ wind speeds for the region in winter and may have a greater forcing contribution from the Blackadar mechanism (Blackadar, 1957).

\subsection{Sensitivity analyses: LLJ detection algorithm}

\section{(i) Initial demonstration of sensitivity to LLJ definition}

Any LLJ analysis is naturally dependent on the detection algorithm applied. Thus, a sensitivity analysis is performed using differing LLJ detection thresholds (see Table 2). The impact of selecting different thresholds (five different fixed thresholds ranging from 1 to $5 \mathrm{~m} \mathrm{~s}^{-1}$ in increments of $1 \mathrm{~m} \mathrm{~s}^{-1}$ and five different variable thresholds ranging from $10 \%$ to $50 \%$ in increments of $10 \%$ ) is illustrated in Fig. 7 for the WRF grid cell that exhibited the highest LLJ frequency in 
Table 3. Marginal probabilities of LLJs when each of the fixed selection criteria are applied. Results are shown for hourly wind speed profiles from the single grid cell of highest LLJ frequency according to the seasonal study previously developed.

\begin{tabular}{lrrrrr}
\hline Criteria group & 1 & 2 & 3 & 4 & 5 \\
\hline Fixed criterion threshold $\left(\mathrm{m} \mathrm{s}^{-1}\right)$ & 1 & 2 & 3 & 4 & 5 \\
LLJ frequency & 0.4110 & 0.2234 & 0.1116 & 0.0517 & 0.0198 \\
\hline
\end{tabular}

Table 4. Marginal probabilities of LLJs when each of the variable selection criteria are applied. Results are shown for hourly wind speed profiles from the single grid cell of highest LLJ frequency according to the seasonal study previously developed.

\begin{tabular}{lrrrrr}
\hline Criteria group & 1 & 2 & 3 & 4 & 5 \\
\hline Variable criterion threshold (percent of maximum LLJ wind speed) & 10 & 20 & 30 & 40 & 50 \\
Variable: LLJ frequency & 0.4087 & 0.2336 & 0.0970 & 0.0326 & 0.0132 \\
\hline
\end{tabular}

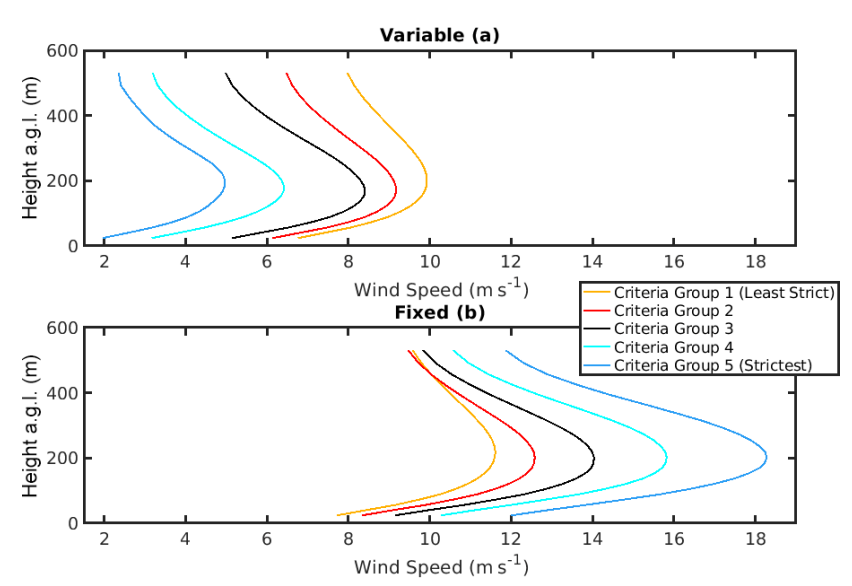

Figure 7. Temporal mean LLJ wind speed profiles extracted by each criterion - variable (a) and fixed (b) - colored by criteria group (criterion utilized for seasonal analysis is shown in red as part of Criteria Group 2). Temporal mean wind speed profiles per group are calculated from LLJ events as described in frequencies in Tables 3 and 4 .

the preceding seasonal analysis (grid cell location indicated in Fig. 2). Sensitivity is firstly demonstrated for a single grid cell to concisely prove sensitivity without confounding factors related to terrain elevation. Domain-wide frequencies are presented in Fig. 10 for the most frequently used LLJ definitions and indicate that there is terrain-related sensitivity to the LLJ criteria employed. Variable and fixed criteria in each group are studied separately to examine the type of LLJ extracted by each unique definition. In other words, in every case, either a fixed or variable criterion is applied; the criteria are not used in tandem throughout the study. As shown in Fig. 7, the time-averaged mean wind speed profiles during hours identified as exhibiting LLJs using these 10 different selection criteria differ greatly. As the threshold used in the variable criterion increases, i.e., as the difference between the LLJ core wind speed and the wind speeds above and below that level increases, the mean wind speeds at the nominal wind turbine hub height and throughout the entire lowest $530 \mathrm{~m}$ of the model output decrease (Fig. 7a). Conversely, as the fixed threshold for the difference in absolute wind speed of the jet core and above and below it increases from 1 to $5 \mathrm{~m} \mathrm{~s}^{-1}$, wind speeds at the nominal wind turbine hub height and throughout the entire lowest $530 \mathrm{~m}$ of the model output increase. These changes are non-linear and are most profound close to the mean height of the LLJ core (approx. $200 \mathrm{~m}$ a.g.l.). Alteration of the stringency of the threshold has a considerably more modest impact on the height at which the mean jet core is manifest (Fig. 7). Application of increasingly stringent criteria (higher thresholds) causes the overall frequency of LLJs to decrease (Tables 3 and 4). Interestingly, the absolute frequency of LLJs is approximately consistent for criteria groups across the two methods (fixed and variable thresholds) (Tables 3 and 4).

However, as stated previously, the mean wind speed profiles differ markedly. For criteria group 2, which features the fixed and variable criteria used (independently and in conjunction) throughout the literature (20\% variable, $2 \mathrm{~m} \mathrm{~s}^{-1}$ fixed), the temporal mean wind speed maximum for LLJs extracted with the variable criterion is approximately $4 \mathrm{~m} \mathrm{~s}^{-1}$ lower than that of the fixed (Hallgren et al., 2020; Andreas et al., 2000; Kalverla et al., 2019; Duarte et al., 2012).

Despite similarity in the frequency with which LLJs are detected, as shown in Tables 3 and 4, the two criteria types (even in the least strict criteria group of $1 \mathrm{~m} \mathrm{~s}^{-1}$ fixed, $10 \%$ variable) identify a substantial number of different, distinct LLJ events. For the least stringent criteria group (lowest thresholds), of the total number of times that an LLJ is identified between the two criteria (the intersection of identified LLJ), the criteria extract different LLJ events $20 \%$ of the time (i.e., an LLJ is identified by one type of criterion but not the other). Thus, the relative frequency of disagreement is $20 \%$. This relative frequency of disagreement increases to nearly $40 \%$ for the second criteria group $\left(2 \mathrm{~m} \mathrm{~s}^{-1}\right.$ fixed, $20 \%$ variable), in which the variable and fixed criteria identify different LLJ profiles $40 \%$ of the time (thus they iden- 


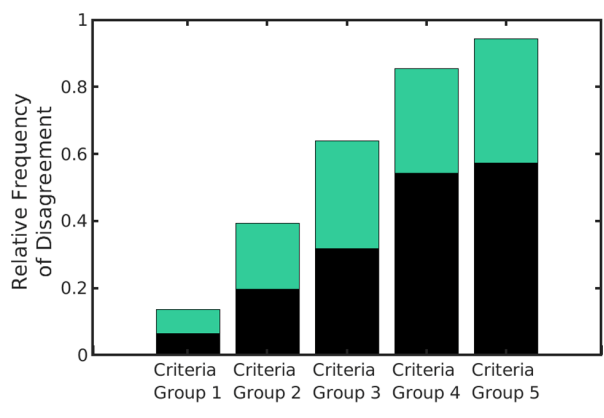

Figure 8. Relative frequency of disagreement of LLJ identification between analyses using a fixed threshold and a variable threshold. In each criteria group, the variable and fixed thresholds are applied separately to the same hourly wind speed profiles to generate frequencies of LLJ identification for each type of threshold. Bars represent the proportion of LLJ identifications in which one criterion identifies an LLJ while the other does not (the relative disagreement in LLJ identification between fixed and variable criteria). Bars are shaded by the proportion of disagreements in which an LLJ is identified by fixed criteria but not variable (black) and an LLJ is identified by variable criteria but not fixed (green). Calculated from hourly output from a single grid cell with the highest LLJ frequency as indicated by the seasonal analysis (see Fig. 1 for location).

tify the same hourly WS profiles as LLJs $60 \%$ of the time) (Fig. 8). The frequency with which LLJs are identified by variable criteria but not by fixed, and vice versa, is relatively equal for the first three criteria groups. However, as threshold stringency increases (criteria groups 4 and 5), LLJs are more likely to be identified by fixed criteria than when the variable threshold is applied, and the identified LLJ events become more dissimilar, with the two criteria identifying the same LLJ events only $10 \%$ of the time (Fig. 8). These results indicate that the usage of varying LLJ definitions in the literature (a fixed threshold only or a fixed and variable threshold in tandem) potentially results in frequent identification of entirely different LLJ events. Results from this sensitivity study inform choice of criterion for the initial study; both criteria types are biased toward certain maximum LLJ speeds, and choosing a criterion in the least strict group could result in LLJ wind speed profiles that are hardly differentiable from non-LLJ (as indicated by the lower shear displayed in jets extracted in criteria group 1). Further, criteria group 2 features definitions most relevant to previous studies, and the variable criterion chosen allows for analysis of LLJs that might have been previously undefined through usage of only a fixed criterion (as is common in the previous literature).

\section{(ii) Sensitivity of LLJ definition across entire domain (ensemble sensitivity)}

Ensemble characteristics for LLJs extracted with each definition are analyzed to better understand LLJs extracted with each definition. Domain-wide LLJ frequencies are analyzed for the two most common definitions used in the LLJ lit- erature (criteria group 2) and indicate where, in a domain with complex terrain, each type of LLJ (as extracted by the definitions) is likeliest to be extracted. Results of the sensitivity analyses applied to all grid cells within D03 and all hours during the 6-month period are consistent with those from the individual grid cell with the highest LLJ frequency. Usage of a fixed threshold extracts LLJs with higher wind speed maxima overall; across all criteria groups, the ensemble median LLJ height is higher by approximately $20 \mathrm{~m}$ when fixed thresholds are applied (Fig. 9a). Use of a higher variable threshold for LLJ detection (i.e., going from a deviation in wind speeds of $10 \%$ around the jet maximum to $50 \%$ ) leads to a modest decline in the median height of the LLJ (Fig. 9a) and a marked decline in LLJ duration from 6 to $2 \mathrm{~h}$ (Fig. 9c). Use of a stricter fixed threshold leads to an even smaller change in the median height of the LLJ maximum (Fig. 9b). For all three properties, the LLJ cases become more self-similar (the dispersion of the distributions decreases) as increasingly selective criteria are applied (Fig. 9). For all levels of strictness considered, variable criteria extract more cases that are identified as outliers (i.e., lie beyond 1.5 times the interquartile range from the 75th percentile) in terms of the LLJ duration than fixed criteria (Fig. 9c). As in results for an individual grid cell shown in Fig. 7, as the absolute threshold applied for LLJ detection increases, the LLJ maximum wind speed increases, whilst the converse is true for increasing the variable criteria threshold (Fig. 9b).

For criteria group 2 featuring LLJ definitions commonly used in the literature separately or in tandem, $\left(2 \mathrm{~m} \mathrm{~s}^{-1}\right.$ fixed, $20 \%$ variable), the spatial distribution of LLJ frequency is sensitive to the threshold employed, particularly in regions of sloping and complex terrain (Fig. 10). As illustrated by Fig. 8 using output for a single grid cell, it is evident that algorithms using the two different criteria flag different periods as indicative of the presence of LLJs. The tendency for variable criteria to extract lower-wind-speed LLJs and for fixed criteria to extract higher-speed LLJs is potentially evident in frequency differences between groups across varying terrain; for the area of high elevation in the west of the state, fixed criteria extract a higher frequency of LLJs than variable criteria on the western side of the terrain elevation. Conversely, on the eastern side, LLJs are extracted with higher frequency when a variable criterion is utilized. It is thus possible that variations in flow velocity over complex terrain contribute to the frequency differences in LLJs extracted by each criterion (Helbig et al., 2016). Areas with lower LLJ wind speed as defined in Fig. 6 coincide with areas of higher LLJ frequency when a variable criterion is applied. The same is true for higher LLJ speeds when a fixed criterion is applied.

Higher LLJ speeds in the surveyed region correspond to an atmosphere that is near-neutral and enhanced TKE (Aird et al., 2020). It is possible that a fixed criterion is more appropriate than a variable criterion to ensure that high-speed LLJs are extracted reliably. Shorter-duration, higher-speed jets with enhanced TKE, such as those observed in higher 

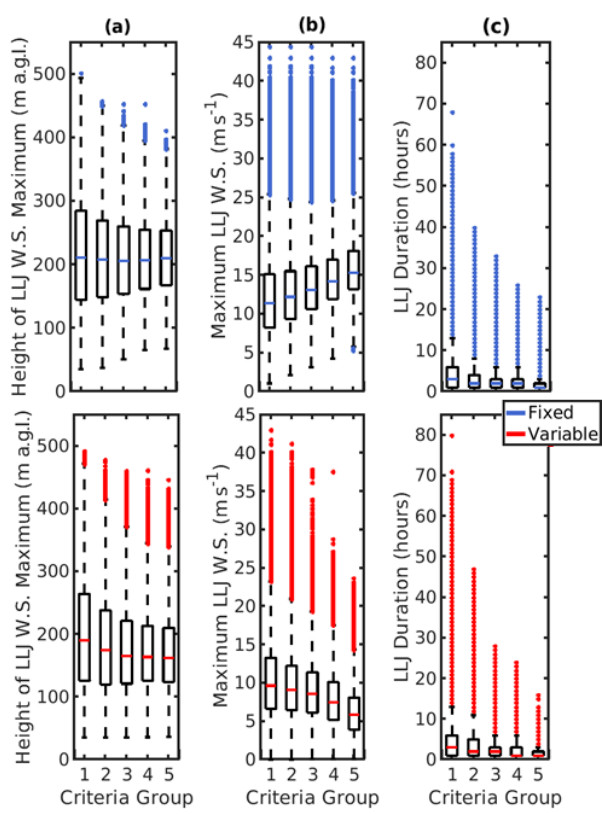

Figure 9. Box-whisker plots for definition-wise distributions of spatiotemporal LLJ characteristics: (a) jet core height, (b) jet core speed and (c) jet duration over the entire domain. Note: the whiskers on the boxplots extend from the 75 th percentile to +1.5 times the inter-quartile range and from the 25 th percentile to 1.5 times the inter-quartile range. Points beyond those values are defined as outliers and plotted as individual points.

frequency over complex terrain elevation, are less likely to be captured with the usage of a variable criterion (Fig. 10). In contrast, the variable criterion extracts a higher number of LLJs with low-magnitude wind speed maxima and higher duration. The decreased wind speeds of the LLJs captured under a variable criterion likely correspond to more stable conditions and decreased TKE. These characteristic differences further account for the higher frequency of LLJs extracted under a variable criterion in the region of the state with less complex and sloping terrain (Fig. 10). The inference is that the two detection approaches, regardless of the precise thresholds applied, may exhibit differing ability to identify the presence of an LLJ depending on the causal mechanism, which has implications for regional LLJ studies in complex terrain.

\subsection{Sensitivity analyses: output resolution}

In this analysis, an LLJ detection algorithm using a variable threshold of $20 \%$ is applied to output from the WRF simulation using the original vertical resolution, output sampled from every second level and output sampled from every fourth vertical level (Table 5, Fig. 11). The profiles are not linearly interpolated between vertical layers; the LLJs can only exhibit maxima at heights at the 25,13 and 7 vertical layers considered (to parallel the extraction of LLJ pro- files from observational data in which there are a number of fixed data points). The spatiotemporal mean LLJ core wind speed differs markedly according to the vertical resolution (Table 5). When the model output is sampled at onequarter of the simulation vertical resolution, the mean maximum (jet core) wind speed is $1 \mathrm{~m} \mathrm{~s}^{-1}$ lower than when the LLJ detection algorithm is applied to output at the model resolution (i.e., all 25 levels below 531 ma.g.l.) (Fig. 11, Table 5). Output down-sampled to one-quarter resolution also exhibits a substantially lower mean LLJ core height $(156.43 \mathrm{~m})$ than when the analysis is applied to output at full resolution $(182.64 \mathrm{~m})$. This reduction in the height of the wind speed maxima results in a higher percentage of LLJ cores falling within the nominal wind turbine rotor plane of $50-150 \mathrm{~m}$ a.g.l. The spatiotemporal mean duration and frequency of LLJs are also lower in the reduced-resolution output (Table 5).

The usage of a polynomial interpolation to account for lower output resolution when extracting LLJs is shown to reduce sensitivity in LLJ characteristics (Table 6). Winter wind speed output at full resolution is firstly analyzed for LLJs under the $20 \%$ variable criterion. From this, wind speed profiles corresponding with identified LLJs are sampled at quarter resolution (resulting in wind speed profiles comprised of seven vertical layers). A sixth-degree polynomial is then fit to each of these wind speed profiles to extrapolate the non-linear LLJ shape between wind speed values at each layer. After creation of the polynomial, the quarter-resolution height above ground level for each profile is linearly interpolated to that of the full-resolution output (25 layers). These linearly interpolated height values are then input into the polynomial function for each wind speed profile to extrapolate the quarter-resolution output into full-resolution output. These profiles (extrapolated to full resolution from quarter resolution) are then input into the LLJ detection algorithm (20\% variable), and resulting ensemble characteristics are compared to LLJ characteristics from full-resolution profiles and the original down-sampled quarter-resolution profiles.

LLJ characteristics (particularly jet core height) are sensitive to the model output resolution, but spatial variability appears to be less sensitive. The temporal mean LLJ frequency and duration in each WRF grid cell, as extracted from quarter-resolution and full-resolution output, are normalized relative to their respective domain-wide maximum values (Fig. 12). This process defines the domain-wide variations in LLJ frequency and duration for full-resolution and quarterresolution output irrespective of the numerical values of each. The resulting normalized LLJ frequency and durations for both resolutions allow for comparison of spatial variability. Most regions (irrespective of terrain elevation) display low sensitivity to reductions in resolution (Fig. 12). Maximum positive and negative differences between normalized frequency and duration range from approximately -0.05 to 0.16 , respectively. Regions of maximum spatial variability differences occur sporadically throughout the domain and do 

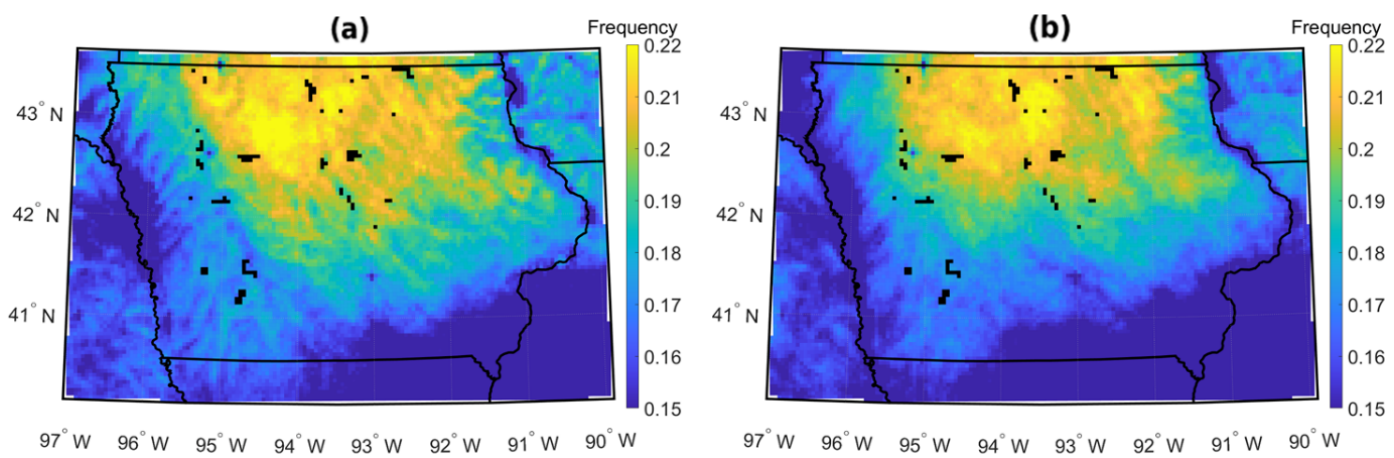

Figure 10. Spatial distributions of LLJ frequency computed using a detection algorithm with a (a) $20 \%$ variable threshold and a (b) $2 \mathrm{~m} \mathrm{~s}{ }^{-1}$ fixed threshold.

(a)

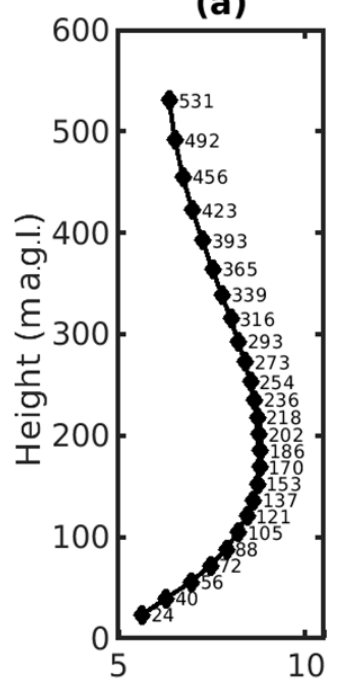

(b)

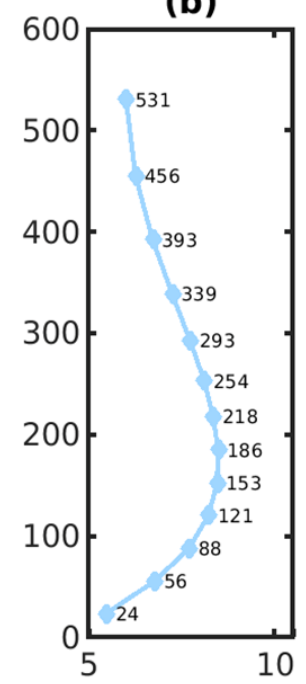

(c)

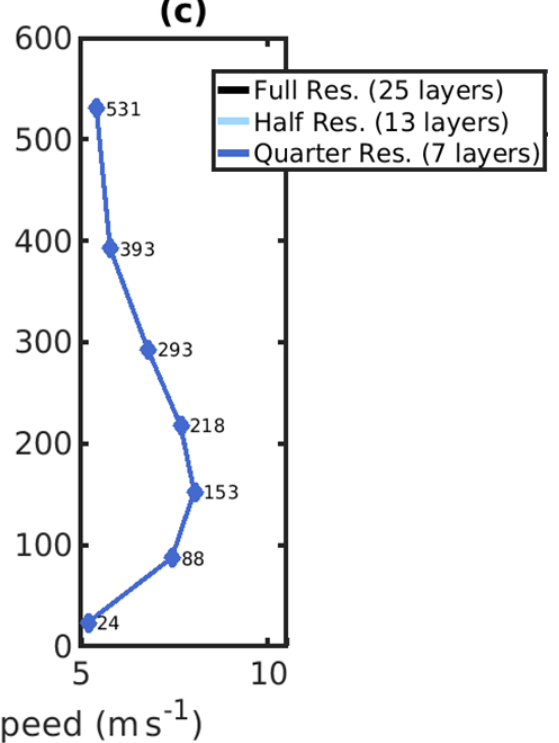

Figure 11. Mean wind speed profiles for output at (a) full resolution (25 layers, no down-sampling), (b) half resolution (13 layers, output down-sampled to every other layer) and (c) quarter resolution (7 layers, output down-sampled to every fourth layer). Note: layers are connected linearly for figure visibility, but the LLJ wind speed maxima can only occur at the heights defined at the vertical layers (25, 13 and 7 heights, respectively, for each resolution).

not correspond with terrain elevation. Regardless of these areas of high variability difference, the spatial patterns of LLJ frequency and duration are comparatively insensitive to the down-sampling of vertical resolution for most of the domain. Further, regions identified as having the highest frequency and temporal mean duration (the highest $5 \%$ of each quantity) of LLJs are similar when the LLJ detection algorithm is applied to output at the original vertical resolution and one-quarter vertical resolution (Fig. 12a). However, there is more divergence in spatial variation in LLJ duration than frequency when these contours are considered (Fig. 12b). This potentially indicates that inter-study comparisons of regions of high LLJ frequency (and less so duration) may be possible, even under reduced vertical resolution of observational data and/or model output.
Ensemble LLJ characteristics display sensitivity to the resolution of wind speed profiles, but this can be mitigated through extrapolating the wind speed profile to higher resolution through a polynomial fit. This sensitivity appears to be consistent across the domain and irrespective of terrain complexity as regions of highest LLJ frequency and duration are preserved when LLJs are extracted from full-resolution wind speed profiles and manually down-sampled wind speed profiles. Though a $20 \%$ variable criterion is utilized for this sensitivity study, it is possible that usage of a different criterion might affect the results and increase the efficacy of the polynomial fit in resolving lower-resolution LLJ profiles. For example, for higher-wind-speed LLJs (wind speed maximum $>17 \mathrm{~m} \mathrm{~s}^{-1}$ ) that are extracted by the fixed criterion, shear across the rotor plane remains relatively constant (Aird 
Table 5. Spatially and temporally averaged LLJ properties as a function of model output vertical resolution.

\begin{tabular}{lccccc}
\hline & $\begin{array}{c}\text { Mean } \\
\text { jet } \\
\text { core } \\
\text { wind } \\
\text { speed } \\
\left(\mathrm{m} \mathrm{s}^{-1}\right)\end{array}$ & $\begin{array}{c}\text { Mean } \\
\text { height } \\
\text { of jet } \\
\text { core } \\
\text { (m a.g.1.) }\end{array}$ & $\begin{array}{c}\text { Mean LLJ } \\
\text { duration } \\
\text { (h) }\end{array}$ & $\begin{array}{c}\text { Percent of LLJ } \\
\text { with jet } \\
\text { cores } \\
\text { within } \\
\text { the rotor } \\
\text { plane }\end{array}$ & $\begin{array}{c}\text { Spatiotemporal } \\
\text { LLJ frequency }\end{array}$ \\
\hline Sensitivity analysis B: down-sampling of output & & & \\
\hline Full resolution: 25 vertical levels & 9.55 & 182.64 & 3.52 & 39.15 & $17.32 \%$ \\
13 vertical levels (0.5 resolution) & 9.18 & 172.89 & 3.35 & 41.83 & $15.12 \%$ \\
7 vertical levels (0.25 resolution) & 8.53 & 156.43 & 2.98 & 46.95 & $10.75 \%$ \\
\hline
\end{tabular}

Table 6. For winter months (December, January, February) - spatially and temporally averaged LLJ properties as a function of model output vertical resolution for full-resolution and quarter-resolution output as well as quarter-resolution output extrapolated to full-resolution output through polynomial interpolation.

\begin{tabular}{lccc}
\hline & $\begin{array}{c}\text { Mean } \\
\text { jet } \\
\text { core } \\
\text { wind } \\
\text { speed } \\
\left(\mathrm{m} \mathrm{s}^{-1}\right)\end{array}$ & $\begin{array}{c}\text { Mean } \\
\text { height } \\
\text { of jet } \\
\text { core } \\
(\mathrm{m} \mathrm{a.g.1.)}\end{array}$ & $\begin{array}{c}\text { Percent of LLJ } \\
\text { with jet } \\
\text { cores } \\
\text { within } \\
\text { the rotor } \\
\text { plane }\end{array}$ \\
\hline Extrapolation to full-resolution output from quarter-resolution output & \\
\hline Full resolution: 25 vertical levels & 9.38 & 182.74 & 39.64 \\
Quarter resolution extrapolated to full resolution & 9.33 & 175.94 & 43.53 \\
7 vertical levels (quarter resolution) & 8.34 & 158.15 & 50.73 \\
\hline
\end{tabular}

et al., 2020). In contrast, LLJs exhibiting lower wind speed maxima, as are more commonly extracted by the variable criterion (wind speed maximum between 5 and $11 \mathrm{~m} \mathrm{~s}^{-1}$ ), exhibit a nearly linear decrease in rotor plane shear with an increase in height above ground level These differences are attributed to lower jet core maximum heights for LLJs extracted with variable criteria (Figure 9). Thus, it is possible that extrapolating the LLJ profile from lower-resolution wind speed profiles as extracted from a fixed criterion would prove to be more effective due to more constant shear and higher wind speed maxima.

\section{Conclusions}

High-resolution WRF simulations over the state of Iowa for December 2007-May 2008 are analyzed to generate a seasonal analysis of LLJs over the state and to assess the implications for wind energy resources and operating conditions. LLJ properties considered are maximum wind speed, height of the wind speed maximum, frequency, duration and flow direction. Using a detection algorithm in which the wind speed above and below the LLJ must decrease by at least $20 \%$ of the jet core wind speed, approximately $95 \%$ of LLJs have wind speed maxima between 3 and $25 \mathrm{~m} \mathrm{~s}^{-1}$, and the mean, modal and median heights of the LLJ core are approximately 183, 125 and $174 \mathrm{~m}$, respectively. LLJs are found to be associated with low TKE across the rotor plane (50$150 \mathrm{ma.g.1.}$ ), to occur most frequently under stable conditions, and to cause comparatively high positive and occasionally negative wind shear across the rotor plane. LLJs are most common in the north of the state. Locations of highest regional LLJ frequency and duration are found to exhibit seasonal variability, likely due to changes in flow direction and the interaction between regional and locally forced flows.

Assessments of the sensitivity to the precise detection algorithm applied and output resolution are also performed. The first sensitivity analysis is conducted at full model output resolution and is designed to determine the sensitivity of LLJ characteristics to changes in LLJ definition. Two common types of criteria for LLJ definition are studied, labeled as variable and fixed criteria. Five criteria in each definition are considered (five variable, five fixed) and are grouped by criteria strictness, ranging from $1 \mathrm{~m} \mathrm{~s}^{-1}$ (fixed) to $10 \%$ (variable) for the least strict criteria group (criteria group 1) and $5 \mathrm{~m} \mathrm{~s}^{-1}$ (fixed) to $50 \%$ (variable) for the strictest (criteria group 5). Sensitivity to LLJ definition is first illustrated for a single grid cell in the domain that exhibits the highest value of temporal LLJ frequency. Using different LLJ definitions is 


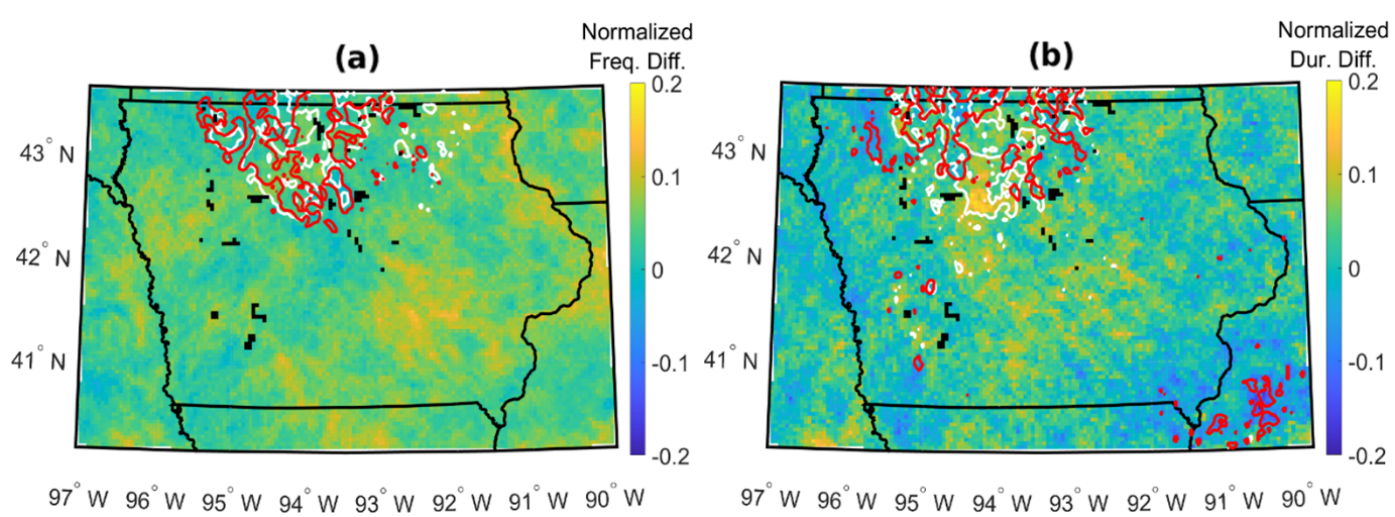

Figure 12. Mean spatial results for December 2007-May 2008, inclusive. Maps colored by difference in (a) normalized LLJ frequency and (b) normalized LLJ duration for output at full resolution and down-sampled to seven layers. Contours represent regions of highest $5 \%$ of (a) LLJ frequency and (b) LLJ duration for output at full resolution (white) and down-sampled to seven layers (red).

shown to identify not just different frequencies of LLJs but also different LLJ events. When considering all LLJs identified by the least strict criteria group, the definitions are shown to extract different LLJs for nearly $20 \%$ of the time. For the second criteria group that features LLJ definitions used in the previous LLJ literature $\left(2 \mathrm{~m} \mathrm{~s}^{-1}\right.$ fixed and $20 \%$ variable), the two definitions extract different LLJs (i.e., one definition flags an LLJ, while the other does not) $40 \%$ of the time. This might suggest that combined criteria using a minimum fixed criterion of 2 or $2.5 \mathrm{~m} \mathrm{~s}^{-1}$ combined with a $20 \%$ or $25 \%$ variable criterion will provide more robust results. Using output from all grid cells within the state of Iowa, it is shown that all LLJ characteristics are sensitive to changes in LLJ definition. LLJs extracted with each definition also likely differ in their causal mechanisms as domain-wide sensitivities to the LLJ definition correspond to differences in terrain elevation and complexity. LLJs as extracted by fixed criteria are predominantly characterized by higher speeds and shorter durations. LLJs extracted by a variable criterion exhibit a higher duration and lower wind speed maxima. In the context of previous work, lower LLJ wind speed maxima as extracted by variable criteria correspond to more stable conditions and decreased TKE, further explaining the increase in LLJ duration. The difference in LLJ types as extracted by each definition corresponds to terrain complexity; in the region of the state with less complex and sloping terrain, a higher frequency of LLJs is extracted with the variable criterion. The previous literature implements either a fixed criterion (most common) or a fixed and variable criterion in tandem. Thus, it is possible that for regions with less complex terrain, a variable criterion must be implemented to adequately capture all wind speed profiles with LLJ behavior. The converse is true for employing a fixed criterion: to adequately capture higherspeed, shorter-duration LLJs such as those that occur more frequently over complex and sloping terrain, it is pertinent to employ a fixed criterion. Thus, the usage of both a variable and fixed criterion to extract LLJs is recommended. Fu- ture work to explore the impact of LLJ definitions in offshore conditions is warranted.

A second sensitivity study is conducted to determine the sensitivity of LLJ characteristics to changes in vertical resolution of the wind speed output. WRF output is downsampled to one-half and one-quarter of the simulation resolution prior to application of the LLJ detection algorithm. All LLJ characteristics considered are found to be sensitive to reductions in wind speed profile vertical resolution, but, as expected, characteristics calculated at 0.5 vertical resolution exhibit small percent differences from values at full vertical resolution when compared to those calculated at 0.25 resolution, indicating that sensitivity to vertical resolution of wind speed data is non-linear. An implementation of a polynomial interpolation to extrapolate quarter-resolution output to full-resolution output is shown to reduce sensitivities of LLJ characteristics to the output resolution. While LLJ frequency and duration are sensitive numerically to output resolution, there is good agreement for the spatial variability in those properties. These findings indicate that, while numerical values among LLJ studies may differ due to changes in wind speed profile vertical resolution, regions of high LLJ frequency may be correctly identified. Based on findings, employing a polynomial interpolation to enrich the number of data points in the wind speed profile may prove beneficial in resolving ensemble LLJ characteristics.

Data availability. All of the hourly WRF output is available upon request from the authors via the DoE HPPS system.

Author contributions. JAA, RJB and SCP jointly designed the analysis framework. JAA, RJB and SCP developed methods. JAA designed the sensitivity study analysis. JAA developed the figures and drafted the initial paper with input from RJB and SCP. TJS performed the WRF simulations, and SCP obtained the com- 
puting resources. SCP and RJB also contributed to the writing of the final paper.

Competing interests. The authors declare that they have no conflict of interest.

Disclaimer. Publisher's note: Copernicus Publications remains neutral with regard to jurisdictional claims in published maps and institutional affiliations.

Acknowledgements. The authors gratefully acknowledge the US Department of Energy (DoE) (DE-SC0016438 and DESC0016605), the National Science Foundation (NSF) Graduate Research Fellowship Program (DGE-1650441), and computing resources from the NSF (ACI-1541215 and TG-ATM170024) and DoE (DE-AC02-05CH11231). The authors also gratefully acknowledge the two reviewers for their insightful and helpful comments and suggestions.

Financial support. This research has been supported by the US Department of Energy, Office of Science (grant nos. DESC0016438, DE-SC0016605 and DE-AC02-05CH11231); the National Science Foundation, Directorate for Education and Human Resources (grant no. DGE-1650441); and the National Science Foundation, Directorate for Computer and Information Science and Engineering (grant nos. ACI-1541215 and TG-ATM170024).

Review statement. This paper was edited by Katherine Dykes and reviewed by two anonymous referees.

\section{References}

Aird, J. A., Barthelmie, R. J., Shepherd, T. J., and Pryor, S. C.: WRF-Simulated Springtime Low-Level Jets Over Iowa: Implications for Wind Energy, J. Phys. Conf.-Ser., 1618, 062020, https://doi.org/10.1088/1742-6596/1618/6/062020, 2020.

American Clean Power: US Wind Industry Fourth Quarter 2019 Market Report, available at: https://cleanpower.org/wp-content/ uploads/2021/02/ACP_MarketReport_4Q2020.pdf (last access: 20 March 2021), 2020.

Andreas, E. L., Claffey, K. J., and Makshtas, A. P.: Lowlevel atmospheric jets and inversions over the western Weddell Sea, Bound.-Lay. Meteorol., 97, 459-486, https://doi.org/10.1023/A:1002793831076, 2000.

Baas, P., Bosveld, F. C., Klein Baltink, H., and Holtslag, A. A. M.: A climatology of nocturnal low-level jets at Cabauw, J. Appl. Meteorol. Clim., 48, 1627-1642, https://doi.org/10.1175/2009JAMC1965.1, 2009.

Banta, R. M., Newsom, R. K., Lundquist, J. K., Pichugina, Y. L., Coulter, R. L., and Mahrt, L.: Nocturnal Low-Level Jet Characteristics Over Kansas During Cases-99, Bound.-Lay. Meteorol., 105, 221-252, https://doi.org/10.1023/A:1019992330866, 2002.
Barthelmie, R. J., Hansen, K. S., and Pryor, S. C.: Meteorological controls on wind turbine wakes, Proc. IEEE, 101, 1010-1019, https://doi.org/10.1109/JPROC.2012.2204029, 2013.

Barthelmie, R. J., Shepherd, T. J., Aird, J. A., and Pryor, S. C.: Power and Wind Shear Implications of Large Wind Turbine Scenarios in the US Central Plains, Energies, 13, 4269, https://doi.org/10.3390/en13164269, 2020.

Beljaars, A.: The parametrization of surface fluxes in large-scale models under free convection, Q. J. Roy. Meteorol. Soc., 121, 255-270, https://doi.org/10.1002/qj.49712152203, 1995.

Berg, L. K., Riihimaki, L. D., Qian, Y., Yan, H., and Huang, M.: The low-level jet over the Southern Great Plains determined from observations and reanalyses and its impact on moisture transport, J. Climate, 28, 6682-6706, https://doi.org/10.1175/JCLI-D-1400719.1, 2015.

Blackadar, A. K.: Boundary Layer Wind Maxima and Their Significance for the Growth of Nocturnal Inversions, B. Am. Meteorol. Soc., 38, 283-290, https://doi.org/10.1175/1520-0477-38.5.283, 1957.

Bonner, W. D.: Climatology of the Low Level Jet, Mon. Weather Rev., 96, 833-850, https://doi.org/10.1175/15200493(1968)096<0833:cotllj>2.0.co;2, 1968.

Chen, T. C. and Kpaeyeh, J. A.: The synoptic-scale environment associated with the low-level jet of the Great Plains, Mon. Weather Rev., 121, 416-420, https://doi.org/10.1175/15200493(1993)121<0416:tsseaw>2.0.co;2, 1993.

Duarte, H. F., Leclerc, M. Y., and Zhang, G.: Assessing the shear-sheltering theory applied to low-level jets in the nocturnal stable boundary layer, Theor. Appl. Climatol., 110, 359-371, https://doi.org/10.1007/s00704-012-0621-2, 2012.

Gadde, S. N. and Stevens, R. J.: Effect of low-level jet height on wind farm performance, J. Renew. Sustain. Energy, 13, 013305, https://doi.org/10.1063/5.0026232, 2021.

Gevorgyan, A.: A Case Study of Low-Level Jets in Yerevan Simulated by the WRF Model, J. Geophys. Res.-Atmos., 123, 300314, https://doi.org/10.1002/2017JD027629, 2018.

Grachev, A. A., Andreas, E. L., Fairall, C. W., Guest, P. S., and Persson, P. O. G.: The critical Richardson number and limits of applicability of local similarity theory in the stable boundary layer, Bound.-Lay. Meteorol., 147, 51-82, https://doi.org/10.1007/s10546-012-9771-0, 2012.

Gutierrez, W., Araya, G., Basu, S., Ruiz-Columbie, A., and Castillo, L.: Toward Understanding Low Level Jet Climatology over West Texas and its Impact on Wind Energy, J. Phys. Conf.-Ser., 524, 012008, https://doi.org/10.1088/1742-6596/524/1/012008, 2014.

Gutierrez, W., Ruiz-Columbie, A., Tutkun, M., and Castillo, L.: Impacts of the low-level jet's negative wind shear on the wind turbine, Wind Energ. Sci., 2, 533-545, https://doi.org/10.5194/wes2-533-2017, 2017.

Hallgren, C., Arnqvist, J., Ivanell, S., Körnich, H., Vakkari, V., and Sahlée, E.: Looking for an offshore low-level jet champion among recent reanalyses: a tight race over the Baltic Sea, Energies, 13, 3670, https://doi.org/10.3390/en13143670, 2020.

Helbig, N., Mott, R., Van Herwijnen, A., Winstral, A., and Jonas, T.: Parameterizing surface wind speed over complex topography, J. Geophys. Res.-Atmos., 122, 651-667, https://doi.org/10.1002/2016JD025593, 2016.

Higgins, R. W., Yao, Y., Yarosh, E. S., Janowiak, J. E., and Mo, K. C.: Influence of the Great Plains low-level jet on summer- 
time precipitation and moisture transport over the central United States, J. Climate, 10, 481-507, https://doi.org/10.1175/15200442(1997)010<0481:IOTGPL>2.0.CO;2, 1997.

Hoen, B. D., Diffendorfer, J. E., Rand, J. T., Kramer, L. A., Garrity, C. P., and Hunt, H. E.: United States Wind Turbine Database (v4.1), US Geological Survey, American Clean Power Association, and Lawrence Berkeley National Laboratory data release, https://doi.org/10.5066/F7TX3DN0, 2021.

Holton, J. R.: The diurnal boundary layer wind oscillation above sloping terrain, Tellus, 19, 200-205, https://doi.org/10.3402/tellusa.v19i2.9766, 1967.

Jahn, D. E. and Gallus, W. A.: Impacts of Modifications to a Local Planetary Boundary Layer Scheme on Forecasts of the Great Plains Low-Level Jet Environment, Weather Forecast., 33, 11091120, https://doi.org/10.1175/WAF-D-18-0036.1, 2018.

Jiang, X., Lau, N. C., Held, I. M,. and Ploshay, J. J.: Mechanisms of the Great Plains low-level jet as simulated in an AGCM, J. Atmos. Sci., 64, 532-547, https://doi.org/10.1175/JAS3847.1, 2007.

Jiménez-Sánchez, G., Markowski, P. M., Jewtoukoff, V., Young, G. S., and Stensrud, D. J.: The Orinoco Low-Level Jet: An Investigation of Its Characteristics and Evolution Using the WRF Model, J. Geophys. Res.-Atmos., 124, 10696-10711, https://doi.org/10.1029/2019JD030934, 2019.

Kalverla, P. C., Duncan, J. B., Steeneveld, G. J., and Holtslag, A. A. M.: Low-level jets over the north sea based on ERA5 and observations: Together they do better, Wind Energ. Sci., 4, 193209, https://doi.org/10.5194/wes-4-193-2019, 2019.

Kelley, N. D., Jonkman, B. J., Scott, G. N., Bialasiewicz, J. T., and Redmond, L. S.: Impact of coherent turbulence on wind turbine aeroelastic response and its simulation, No. NREL/CP-50038074, NREL - National Renewable Energy Lab, Golden, CO, USA, 2005.

Krishnamurthy, L., Vecchi, G. A., Msadek, R., Wittenberg, A., Delworth, T. L., and Zeng, F.: The seasonality of the great plains low-level Jet and ENSO relationship, J. Climate, 28, 4525-4544, https://doi.org/10.1175/JCLI-D-14-00590.1, 2015.

Lackmann, G. M.: Cold-fontal potential vorticity maxima, the low-level jet, and moisture transport in extratropical cyclones, Mon. Weather Rev., 130, 59-74, https://doi.org/10.1175/15200493(2002)130<0059:CFPVMT>2.0.CO;2, 2002.

Lampert, A., Bernalte Jimenez, B., Gross, G., Wulff, D., and Kenull, T.: One-year observations of the wind distribution and low-level jet occurrence at Braunschweig, North German Plain, Wind Energy, 19, 1807-1817, https://doi.org/10.1002/we.1951, 2016.

Liang, Y. C., Yu, J. Y., Lo, M. H., and Wang, C.: The changing influence of El Niño on the Great Plains low-level jet, Atmos. Sci. Lett., 16, 512-517, https://doi.org/10.1002/as1.590, 2015.

Markowski, P. and Richardson, Y.: Mesoscale Meteorology in Midlatitudes, Wiley-Blackwell, Chichester, UK, 2011.

Mitchell, M. J., Arritt, R. W., and Labas, K.: A climatology of the warm season Great Plains lowlevel jet using wind profiler observations, Weather Forecast., $\quad 10, \quad 576-591$, https://doi.org/10.1175/15200434(1995)010<0576:ACOTWS>2.0.CO;2, 1995.

Mortarini, L., Cava, D., Giostra, U., Acevedo, O., Nogueira Martins, L., Soares de Oliveira, P., and Anfossi, D.: Observations of submeso motions and intermittent turbulent mixing across a low level jet with a 132-m tower, Q. J. Roy. Meteorol. Soc., 144, 172183, https://doi.org/10.1002/qj.3192, 2018.

Nakanishi, M. and Niino, H.: An improved Mellor-Yamada level-3 model: Its numerical stability and application to a regional prediction of advection fog, Bound.-Lay. Meteorol., 119, 397-407, https://doi.org/10.1007/s10546-005-9030-8, 2006.

Nunalee, C. G. and Basu, S.: Mesoscale modeling of coastal lowlevel jets: implications for offshore wind resource estimation, Wind Energy, 17, 1199-1216, https://doi.org/10.1002/we.1628, 2014.

Parish, T. R.: Barrier winds along the Sierra Nevada mountains, J. Appl. Meteorol., 21, 925-930, https://doi.org/10.1175/15200450(1982)021<0925:BWATSN>2.0.CO;2, 1982.

Prabha, T. V., Goswami, B. N., Murthy, B. S., and Kulkarni, J. R.: Nocturnal low-level jet and "atmospheric streams" over the rain shadow region of indian western ghats, Q. J. Roy. Meteorol. Soc., 137, 1273-1287, https://doi.org/10.1002/qj.818, 2011.

Prósper, M. A., Otero-Casal, C., Fernández, F. C., and Miguez-Macho, G.: Wind power forecasting for a real onshore wind farm on complex terrain using WRF high resolution simulations, Renew. Energy, 135, 674-686, https://doi.org/10.1016/j.renene.2018.12.047, 2019.

Pryor, S. C., Shepherd, T. J., Bukovsky, M., and Barthelmie, R. J.: Assessing the stability of wind resource and operating conditions, J. Phys. Conf.-Ser., 1452, 012084, https://doi.org/10.1088/1742-6596/1452/1/012084, 2020a.

Pryor, S. C., Barthelmie, R. J., Bukovsky, M. S., Leung, L. R., and Sakaguchi, K.: Climate change impacts on wind power generation, Nat. Rev. Earth Environ., 1, 627-643, https://doi.org/10.1038/s43017-020-0101-7, 2020b.

Pryor, S. C., Shepherd, T. J., Volker, P. J. H., Hahmann, A. N., and Barthelmie, R. J.: "Wind Theft" from onshore wind turbine arrays: Sensitivity to wind farm parameterization and resolution, J. Appl. Meteorol. Clim., 59, 153-174, https://doi.org/10.1175/JAMC-D-19-0235.1, 2020c.

Rife, D. L., Pinto, J. O., Monaghan, A. J., Davis, C. A., and Hannan, J. R.: Global distribution and characteristics of diurnally varying low-level jets, J. Climate, 23, 5041-5064, https://doi.org/10.1175/2010JCLI3514.1, 2010.

Salvação, N. and Soares, C. G.: Wind resource assessment offshore the Atlantic Iberian coast with the WRF model, Energy, 145, 276-287, https://doi.org/10.1016/j.energy.2017.12.101, 2018.

Schepanski, K., Knippertz, P., Fiedler, S., Timouk, F., and Demarty, J.: The sensitivity of nocturnal low-level jets and near-surface winds over the Sahel to model resolution, initial conditions and boundary-layer set-up, Q. J. Roy. Meteorol. Soc., 141, 14421456, https://doi.org/10.1002/qj.2453, 2015.

Smith, E. N., Gibbs, J. A., Fedorovich, E., and Klein, P. M.: WRF Model study of the Great Plains low-level jet: Effects of grid spacing and boundary layer parameterization, J. Appl. Meteorol., 57, 2375-2397, https://doi.org/10.1175/JAMC-D-170361.1, 2018.

Song, J., Liao, K., Coulter, R. L., and Lesht, B. M.: Climatology of the low-level jet at the southern Great Plains atmospheric boundary layer experiments site, J. Appl. Meteorol., 44, 1593-1606, https://doi.org/10.1175/JAM2294.1, 2005.

Squitieri, B. J. and Gallus, W. A.: WRF forecasts of Great Plains nocturnal low-level jet-driven MCSs. Part II: Differences between strongly and weakly forced low-level 
jet environments, Weather Forecast., 31, 1491-1510, https://doi.org/10.1175/WAF-D-15-0150.1, 2016.

Storm, B., Dudhia, J., Basu, S., Swift, A., and Giammanco, I.: Evaluation of the weather research and forecasting model on forecasting low-level jets: Implications for wind energy, Wind Energy, 12, 81-90, https://doi.org/10.1002/we.288, 2008.

Stull, R. B.: An Introduction to Boundary Layer Meteorology, Kluwer, Dordrecht, the Netherlands, 1988.

Tay, K., Koh, T. Y., and Skote, M.: Characterizing mesoscale variability in low-level jet simulations for CBLASTLOW 2001 campaign, Meteorol. Atmos. Phys., 133, 163-179, https://doi.org/10.1007/s00703-020-00736-3, 2020.

Tewari, M., Chen, F., Wang, W., Dudhia, J., LeMone, M., Mitchell, K., Ek, M., Gayno, G., Wegiel, J., and Cuenca, R.: Implementation and verification of the unified NOAH land surface modelin the WRF model, in: 20th Conference on Weather Analysis and Forecasting/16th Conference on Numerical Weather Prediction, 12-16 January 2004, Seattle, WA, 1115, 10-15, 2004.

Udina, M., Soler, M. R., Viana, S., and Yagüe, C.: Model simulation of gravity waves triggered by a density current, Q. J. Roy. Meteorol. Soc., 139, 701-714, https://doi.org/10.1002/qj.2004, 2012.

Vanderwende, B. J., Lundquist, J. K., Rhodes, M. E., Takle, E. S., and Irvin, S. L.: Observing and Simulating the Summertime Low-Level Jet in Central Iowa, Mon. Weather Rev., 143, 23192336, https://doi.org/10.1175/MWR-D-14-00325.1, 2015.
Wagner, D., Steinfeld, G., Witha, B., Wurps, H., and Reuder, J.: Low level jets over the southern North Sea, Meteorol. Z., 28, 389-415, https://doi.org/10.1127/metz/2019/0948, 2019.

Walton, R. A., Takle, E. S., and Gallus, W. A.: Characteristics of 50-200 m winds and temperatures derived from an Iowa tall-tower network, J. Appl. Meteorol. Clim., 53, 2387-2393, https://doi.org/10.1175/JAMC-D-13-0340.1, 2014.

Weaver, S. J. and Nigam, S.: Variability of the Great Plains low-level jet: Large-scale circulation context and hydroclimate impacts, J. Climate, 21, 1532-1551, https://doi.org/10.1175/2007JCLI1586.1, 2008.

Weaver, S. J., Schubert, S., and Wang, H.: Warm season variations in the low-level circulation and precipitation over the central United States in observations, AMIP simulations, and idealized SST experiments, J. Climate, 22, 5401-5420, https://doi.org/10.1175/2009JCLI2984.1, 2009.

Whiteman, C. D., Bian, X., and Zhong, S.: Low-Level Jet Climatology from Enhanced Rawinsonde Observations at a Site in the Southern Great Plains, J. Appl. Meteorol., 36, 1363-1376, https://doi.org/10.1175/15200450(1997)036<1363:LLJCFE>2.0.CO;2, 1997.

Zhang, C., Wang, Y., and Xue, M.: Evaluation of an $E-\varepsilon$ and Three Other Boundary Layer Parametrization Schemes in the WRF Model over the Southeast Pacific and the Southern Great Plains, Mon. Weather Rev., 148, 1121-1145, https://doi.org/10.1175/MWR-D-19-0084.1, 2020. 